\title{
Automatic Geological Map Generalization for special geobody-A Case Study on Dyke
}

\author{
Wenjing $\mathrm{Li}^{\mathrm{a}}$,b, *, Siyi Li ${ }^{\text {a,b }}$, Hongguo Jia ${ }^{\mathrm{c}}$ \\ ${ }^{a}$ School of Resource and Environmental Engineering, Wuhan University of Science and Technology,wtusm_lwj@126.com, \\ lisiyi96@outlook.com \\ ${ }^{b}$ Industrial Safety Engineering Technology Research Center of Hubei Province \\ ${ }^{c}$ Faculty of Geosciences and Environmental Engineering, Southwest Jiaotong University, lemongg@home.swjtu.edu.cn \\ * Corresponding author
}

\begin{abstract}
Dykes are always closely coexisting with ore veins in deposit, they are of great significance in the revelation of regional geology evolution, prosperity of ore prospecting. This paper presents a method for the generalization of dykes as part of automated geological map generalization progress. Based on the principle of good continuation, dykes were amalgamated preliminarily. Then the reserve quota was calculated on the basis of radical law for the editing of dykes. Finally, the outer shape and internal construction of dykes were simplified. The experiment results show that the generalization method can avoid discontinuity as a prerequisite to retaining formation lithology and characteristics of geological structure. This method offers a new perspective for dealing with exceptional geographic elements while generalizing a geologic map.
\end{abstract}

Keywords: Cartographic generalization, Geological map, Dyke,Principle of continuity,Geological processes

\section{Introduction}

Geological map is one of the main carriers of geology production, and the major tools to serve the economic and social development. It is also one of the main symbols of the degree of geological research, the level of geological science and technology and the degree of social civilization. It has always been highly valued by the governments of various countries and international geoscience organizations (Li,2011).

Geological map is one of the main carriers of geology production, and the major tools to serve the economic and social development. It is also one of the main symbols of the degree of geological research, the level of geological science and technology and the degree of social civilization. It has always been highly valued by the governments of various countries and international geoscience organizations (Li,2011).

When it comes to geological map, it doesn' $t$ mean the more detailed the better, on several occasions such as regional geological map, we need to craft the geographic information strategically. When reducing the scale of a geological map it is necessary to emphasise (emphasize) essential geological detail whilst repressing the unimportant. This process of abstraction, termed generalisation (generalization), is acknowledged to be subjective, but nevertheless must attempt to maintain the logical and unambiguous relations between map objects, showing the salient features, possibly in a simplified form, whilst removing unnecessary detail (Loudon, 2000). Experience has shown that manually generalising (generalizing) a digital geological map can be a time consuming and difficult operation, often beyond the scope of the task in hand. The ability to easily and quickly generalise (generalize) such data sets would be highly advantageous, particularly in the context of current digital frameworks (Downs T C,2002).

Dyke is the most common geological body. Because of its relatively small exposure scale, it is often neglected in geological mapping and geological map synthesis or integrated with general geological unit. However, dykes are of great value to reveal the process of the geological evolution of the reconstituted region and guide the practice of production, most of the dykes are always connected with some endogenetic metallic deposits, especially the post orogenic vein group may be closely related to mineralization, and it is expected to be the macro marker (Luo,2008) of the endogenetic metal mineralization, and the vein filling in the recharge channel of the volcano or intrusion (feeder dike) can be used as a primary magma or The representative of the mother magma is used to invert the material composition (Scarrow J H,1998; Westerman D S,2003) of the source area and the eruption of the history of the magma (Michael P,2004; Liang,2005); the dyke filling in some structural fissures, its spatial configuration reacts to the tectonic stress field of (Ancochea E,2003) at that time, and the fissure filled by the dyke is a good channel for the mineralization fluid to rise, making it a good prospecting marker (Ressel M W,2000).

As an ordinary but special geologic body, the generalization mode of dikes inherits the property of general generalization mode, but also has its own characteristics. Therefore, it is of great significance to optimize the treatment of dykes in the comprehensive 
geological map, and to reveal the process of the geological evolution of the reconstituted region and the smooth progress of the prospecting work.

\section{A Review on Current Geological Map Generalization Progress}

\subsection{Generalization process of general geological unit}

Cartographic generalization refers to the proper selection and generalization of compilation data and cartographic objects in the process of compiling maps according to the purpose of compilation. The process of selection in general geological units is divided into two stages: class driven generalization operation and geometrical amalgamation (Downs T C,2002). The class driven generalization operation is to combine all adjacent geological units with similar features on the large scale geological map to form new geological units, and to further complete the preliminary geological unit synthesis. The geometrical amalgamation is to determine the number of geological units that should be preserved from the large scale map to the small scale map in accordance with Topfer's radical law, and then determine the area threshold of the reserved geological unit with the area of the geological units after the preliminary synthesis, so geological units that below the area threshold could be screened out and then merged into the largest geological units adjacent to them.

After completing the selection of geological units, the geology boundary will be simplified by means of exaggeration and displacement.

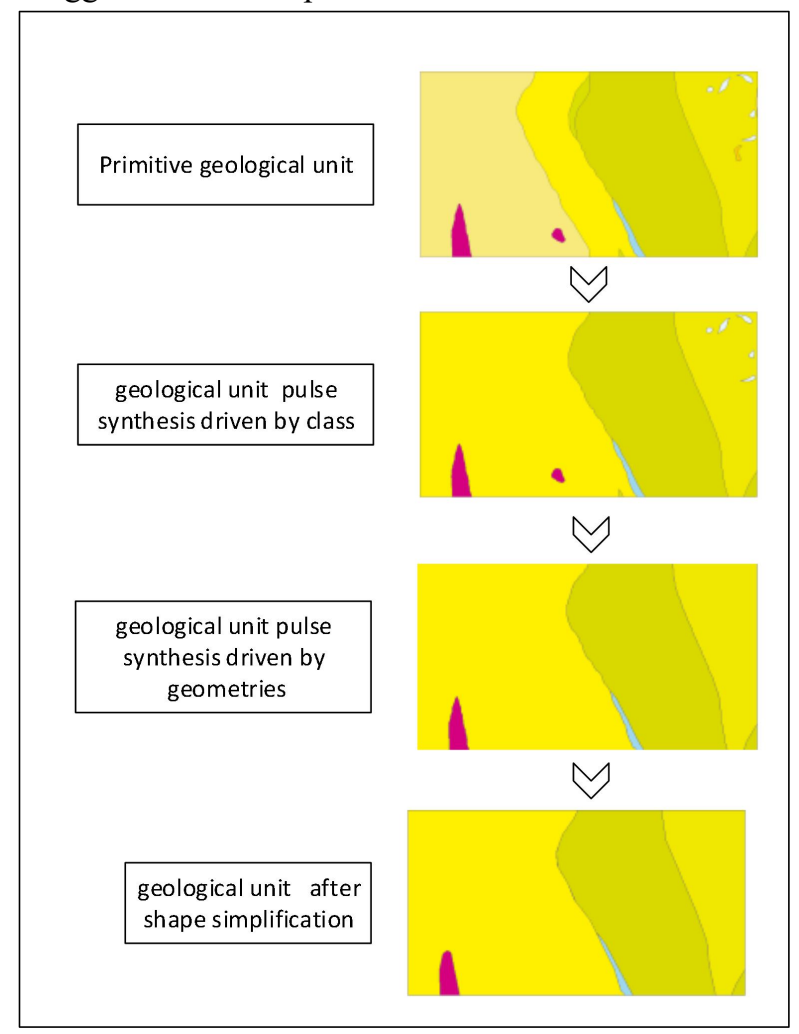

Figure 1. Generalization process of general geological unit.

\subsection{Comprehensive method and improvement of dyke}

The generalization of dykes also basically follows the process of general geological unit.

During the geometrical amalgamation stage, dykes below the area threshold will be removed. However, due to the occurrence of some geological processes, the original complete dykes might show a discontinuous state on a large scale map. If they are handled through computer processing in generic approaches, the dyke (may actually be a part of a larger dyke) which is lower than the present threshold will be removed, to a certain extent. Obstructing the integrity expression of the vein (Figure 2) will also affect the interpretation of the later geological events.

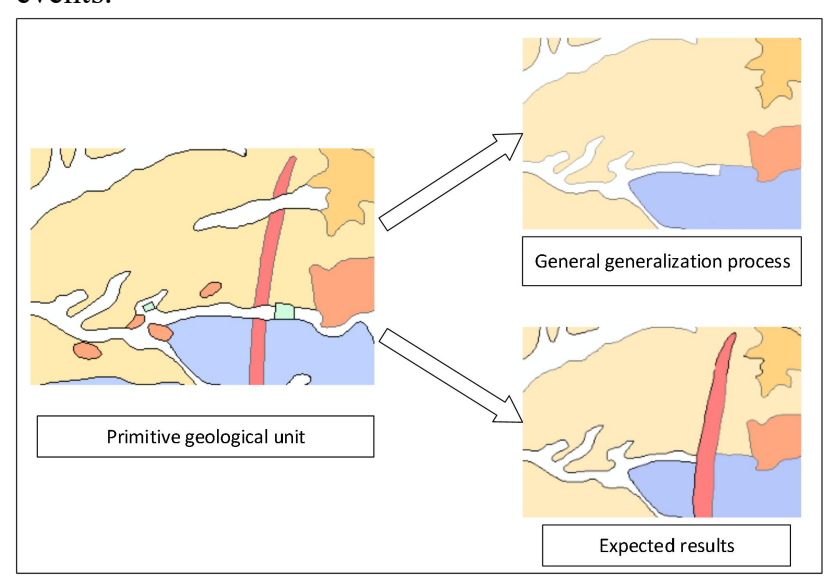

Figure 2. The general geological unit generalization method may cause incomplete expression of dykes.

Therefore, it is necessary to improve the general process of the general geological unit, restore the continuous relationship of the vein in the class driving comprehensive stage, and avoid those homologous veins which should be kept in the discontinuous state but should be preserved in the comprehensive process. The condition of being discarded in the absence of a reservation condition.

The previous general conclusion about the ongoing geologic processes is that it is going very slow. If we eliminate anthropogenic factor as a factor, the reasons for the discontinuity of a complete geological unit can generally consider the following two kinds of nonexclusive reasons: 1) tectonic movement; 2) erosion and accumulation of rivers or sea water.

The discontinuity of a complete geological unit caused by tectonic movement can be subdivided into two cases: faults intersected or slanted through the rock masses to compromise their integrity, the side-to-side or up-anddown motion along fault lines break rock masses into pieces and stagger the pieces (Figure 3a); during the process of magma intrusion, the magma invades the upper covering rock, changing the integrity and adjacency relationship of the original rock. Figure 3B). 


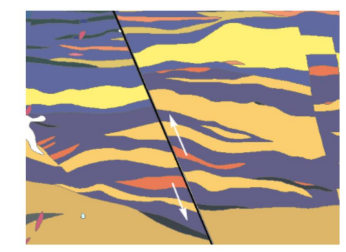

(a) Discontinuity of geologica units caused by faults

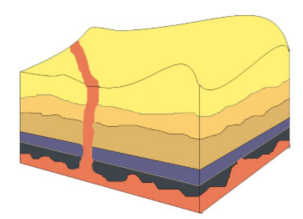

(b) Discontinuity of geological units caused by magmatic activity
Figure 3. Discontinuity of geological units caused by tectonic movement.

The accumulation and erosion of rivers or sea water explain the other case of discontinuity: the lateral erosion, alluvial deposits are deposited on eroded surface geological units, making the original whole form geological unit discontinuous in the veneer of crust. This thesis aims to research the generalization process of dykes, as a part of automated geological map generalization. The main purpose is to find those dykes that associate in deep but manifest discontinuity on surface and then, restore their original stage in geological maps, on the premise that there is no obvious change in the geological structure under the overburden. By analysing the causes of discontinuity, we can reverse the judging criteria of cognate dykes by detecting whether there has been a tectonic movement or whether the erosion and accumulation of rivers or sea water has occurred. After dyke cognate detection, the next step is to affirm whether the cognate dykes are continuous under the crustal surface: the tectonic movement will affect the contiguity relation of geological units at both the surface layer and inside layer, thus change the contiguity relation thoroughly; though the discontinuity caused by shore cutting and deposition has little influence on the geological characteristics under the overburden, therefore the dykes are basically continuous under the overburden. Finally, both the cognate dykes and ordinary dykes will be selected and generalized.

\section{An Introduction to the Relevant Methods of Map Generalization}

\subsection{Principle of continuity}

In this paper, we research on the generalization process of dykes, first move is to return them to the original condition if it' $s$ necessary. Since the geographical phenomena are generally continuous, which means that we can determine the continues relation between the veins with the principle of continuity.

The principle of continuity holds recognizes that the correlation between elements with similar trend is stronger than that between dissimilar trends. The concept derived from the Gestalt principle of organization. As a perception principle, the Gestalt principle of organization plays a vital role in understanding the process of image and map, and its importance in map synthesis has already been recognized. It has also been well applied in road net generalization and fault generalization.
A proximity search, controlled by a search radius and centreline angle tolerance, determined if there were any dikes that can be combined with the target dykes. The preliminarily determined dykes are then be merged as groups with target dykes, will be generalized at last.

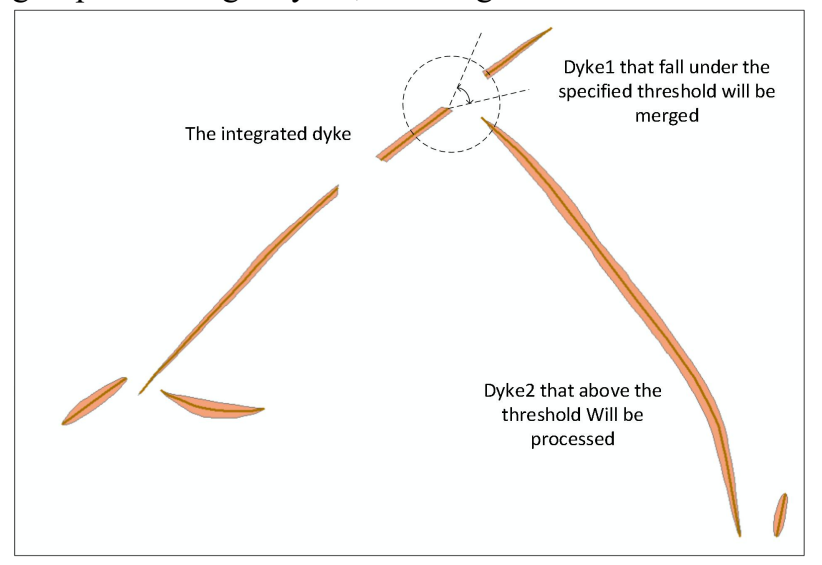

Figure 4. Continuum prediction model of dikes based on continuity principle.

\subsection{Geological processes deduction}

The geological map shows the final result of geological body and geological phenomenon in a certain period. By assuming the premise of its occurrence, the final result of a geological process under the premise is deduced, then comparing with the final result of the real geological body and the geological phenomenon, it is logical to judge whether the premise is correct.

We can use the idea of geological process deduction to judge the contiguity relation between dykes. Under the premise of the assumption that the dyke is intact in the original state, simulate geological process that may cause the dyke to become no longer continuous. If the simulation result is in contradiction with the adjacency relation between geological units and dykes on the present geological map and the position of the adjacent geological units, which means it reject the assumption, the dykes aren't cognate.

\subsection{Extension for Topfer's radical law}

When is integrate a large scale map into a small scale map, the number of objects in the same area will be reduced because of the scale transformation. A certain model is needed to determine the degree of selection of the map after scale transformation relative to the original map.

The Topfer's radical law is the model of the selection of the quantity of ground objects proposed by the German cartographic scientist Topfer in the early 60s. As the main model for the selection of quantity, it continues today. The basic formula is (Downs T C,2002):

$$
C_{b}=C_{a} \sqrt{M_{a} / M_{b}}
$$

Where

$C_{a}$ is the number of classes at source scale,

$C_{b}$ is the number of classes at target scale,

$\mathrm{M}_{a}$ is the source scale denominator,

$\mathrm{M}_{b}$ is the target scale denominator. 
Through the improvement of the Topfer's radical law, we can effectively reduce the impact of imbalance between the area and number of dykes on the selection of ground objects.

\section{Improved Generalization Method of Dyke}

The generalization method of dykes in this paper can be divided into two main steps: the selection of dykes and shape simplification. The selection of dykes is further divided into class driven generalization operation and geometrical amalgamation. In the stage of class driven generalization operation, aiming at the determination of dyke contiguity relation, a process of contiguity relation identification based on principle of continuity and geological process deduction is proposed, potential continuous dykes will be merged preliminarily for the next move. In the stage of geometrical amalgamation, the retention limit of dykes is determined on the basis of the improved Topfer' $\mathrm{s}$ radical law, and the preliminary merged dykes will be ether removed or reserved. Finally, the external contour and internal structure of the veins are simplified.

\subsection{Rock pulse synthesis driven by class}

Because of the importance of the dykes in the transmission of geological events, in the class driven generalization operation, the dykes, as a special kind of geological event, does not participate in the merging process of the geological units with similar characteristics, but solves the determination of dyke contiguity relation in the class driven generalization operation stage, mainly to discuss dyke contiguity relation from the perspective of principle of continuity and geological process deduction.

To simplify the experiment, dykes are abstracted into centerlines. Suppose dykes on the original geological map are set $\left\{L_{1}, L_{2}, \ldots, L_{n}\right\}$. The basic idea of class driven generalization operation is to take into account the continuity between the target dyke and other dykes (the endpoint distance between the dykes is lower than the threshold $\varphi$ and the angle between the dykes is lower than the angular tolerance $\theta$ ) and to determine whether the dykes are contiguity related through the deduction of geological process. Also, it is necessary to point out that the premise of the geological process deduction is that the tectonic movement is limited by the completeness of the structural changes and the principle of continuity. Even before the tectonic movement, dykes are originally integrated, and the deep connection of the deep connections of the dykes causes the reduction of the dykes on the general geological map. The original state is no longer meaningful, so it is necessary to simulate the erosion and accumulation process of the river sea water in the group of the dykes in the group after the preliminary acquisition of the candidate dyke group, to determine whether the hypothesis of the origin of the dyke is reasonable.

a) For dyke $L_{i}(i=1,2, \ldots, n)$, calculate the distance $d_{i j}^{l l}, d_{i j}^{l r}, d_{i j}^{r l}, d_{i j}^{r r}$ between endpoints of

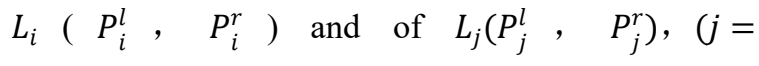

$1,2, \ldots, n, j \neq i)$.

b) Calculate the angle $\alpha_{i j}$ between dyke $L_{i} \quad(i=1$, $2, \ldots, \mathrm{n})$ and dyke $L_{j}(j=1,2, \ldots, n, j \neq i)$.

c) If $\exists \mathrm{d} \in\left\{d_{i j}^{l l}, d_{i j}^{l r}, d_{i j}^{r l}, d_{i j}^{r r}\right\}$ that makes $\mathrm{d}<\varphi, \quad \alpha_{i j}$ $<\theta$, then it is considered that there is a good continuity between $L_{i}$ and $L_{j}$.

d) Join the proximal end of $L_{i}$ and $L_{j}$, set as $l_{i j}$, it is bound to pass through other geological units on the geological map except the dykes. If the geological unit is the product of the erosion and accumulation of river or sea water, it can be considered that $L_{i}$ and $L_{j}$ are contiguity related and can be merged.

e) Repeat step a) to step d) until all the dykes in the collection are identical.

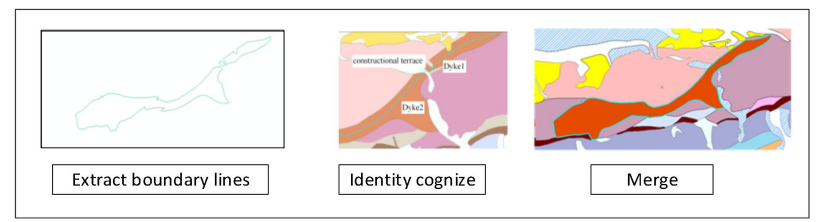

Figure 5. Rock pulse synthesis driven by class.

\subsection{Geometries driven rock pulse synthesis}

After the completion of class driven generalization operation step, dykes with the same contiguity are merged. The merged dykes and those that do not have the merged conditions constitute a new group of dykes $\left\{D_{1}, D_{2}, \ldots D_{k}\right\}$, these dykes will be processed in the geometrical amalgamation stage. In the geometrical amalgamation stage, the load and area threshold of the corresponding scale map are determined according to the general geological unit synthesis method, dykes that below the threshold will be merged into other geological units with similar lithology.

First of all, the new dykes set $\left\{D_{1}, D_{2}, \ldots D_{k}\right\}$ is clustered according to the size of the area to form $C_{a}$ classes, $C_{a}=2 M_{a} / M_{b}$, where $\mathrm{M}_{a}$ is the source scale denominator, $\mathrm{M}_{b}$ is the target scale denominator.

According to the improved Topfer's radical law, the number of dykes that should be reserved on the scale map of the corresponding scale $C_{b}$ is determined, and the area of these classes is sorted and the dykes of the former $C_{b}$ type are taken as the retained dykes in the scale map of the target, the remaining dykes will be abandoned.

Set the abandoned dykes as $\left\{A_{1}, A_{2}, \ldots, A_{h}\right\}$, chooses one and determine its final attribution by examining the attributes of other geological units adjacent to it. If there is only one other geological unit adjacent to it, that is, the chosen dyke is in the state of "isolated island", should be directly merged into the only geological unit adjacent to it, and if there are several other geological units adjacent to it, it is first considered to be combined with its similar lithologic features. When the adjacent geological units are independent of their lithologic characteristics or have little correlation, they are integrated directly according to the size of the area as a comprehensive basis. 


\subsection{Generalizations of geological units}

In order to solve the problem of the adjacent conflict between polygon and polygon, and adjacent conflict inside the polygon, it is necessary to simplify the shape of the dykes. As a part of the generalization process of geological map, dyke generalization should not only consider the problem of the shape simplification of the dykes themselves, but also consider the topological relations of the other geological units adjacent to them.

In the further treatment of the dykes retained in the last step, it is mainly to remove the pieces of the contour to show the general shape features, simplify the external contour and internal structure, keep the similarity between the simplified shapes before and after the shape simplification while taking into account the overall structural similarity between the distribution of the geological units.

\section{Experimental Results and Analysis}

Two kinds of data set from GSJ Database collection are filtered in this paper.

The experimental data include the 1:5 million geological map data (Figure 6a) of Nobeoka and the 1:5 million geological map data (Figure 6b) of the Monotsukayama. The test area (a) map is adjacent to the (b) map of the test area, and the test area (a) contains 9 groups of dyke units, and the test area (b) contains 3 groups of dike units.

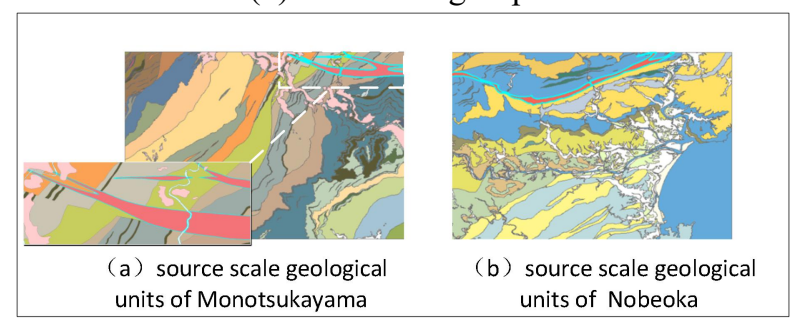

Figure 6. Geological map and general situation of dykes in Experiment1.

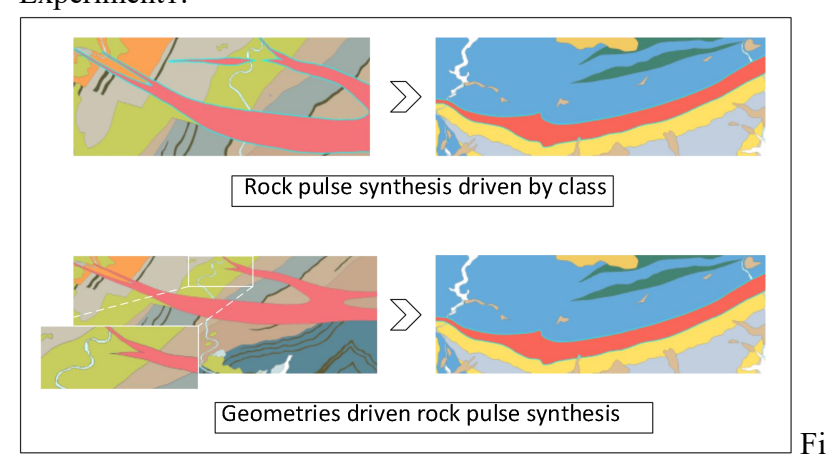

gure 7. Comprehensive results of dyke generalization in Experiment 1.
From the generalization process of the scale 1:5 million to 1:20 million, the centre lines of each dyke were extracted for further comparing and screening. 7 groups of continuous veins were found in the experimental area (a), and 1 group were found in the experimental area (b). After contiguity relation determination, 4 groups of veins in the experimental area (a) showed the similar trend, and the geological bodies between the rocks are all the rivers deposits, in the experimental area (b), 1 group conformed to the conditions. After the merging treatment, the number of dykes in the experimental area (a) changed to 2 , and the number of dykes in the experimental area (b) stay the same. After determining the load and area threshold, one dyke in the experimental area (a) was abandoned and merged into other adjacent geological units.

Finally, the shape of the retained dykes were generalized (Fig. 8).

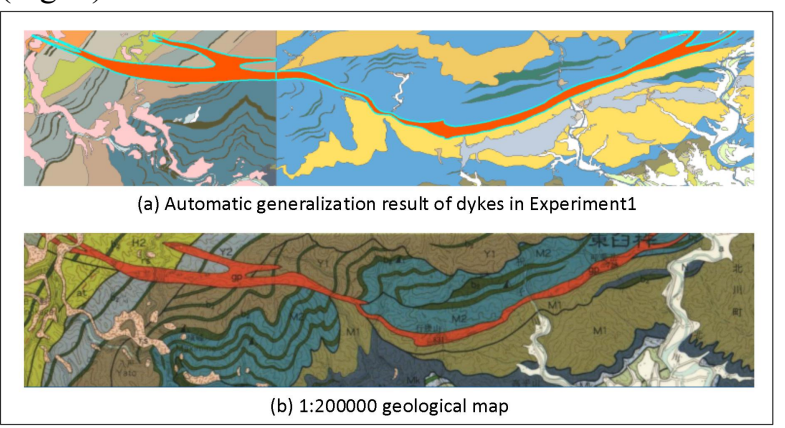

Figure 8 . The automated generalization result compared with geological survey result.

The data of experiment two are from 1:5 million geological map data of Gishiwata (Figure 9a). The experimental area contains 55 dykes. In the selection stage, 4 groups of dykes were considered contiguity related, 51 veins were left after class driven generalization operation; 4 types of dykes are obtained after the cluster is clustered, the class I included 3 dykes, class II included 7 dykes, class III included 13 veins and class IV included 22 dykes; after geometrical amalgamation, dykes in class I and class II were retained; finally, the shape of the dykes were generalized, the final result is in figure $9 b$.

Comparing the experimental results with the existing geological maps of 1:20 million, it is found that the improved dyke generalization method can identify the contiguity related dykes, and the generalization results retained the occurrence of the dykes well. The generalization method of dykes proposed in this paper can effectively avoid the damage of the integrity of the vein under the conditions of retaining the characteristics of the lithology and geological structure. 

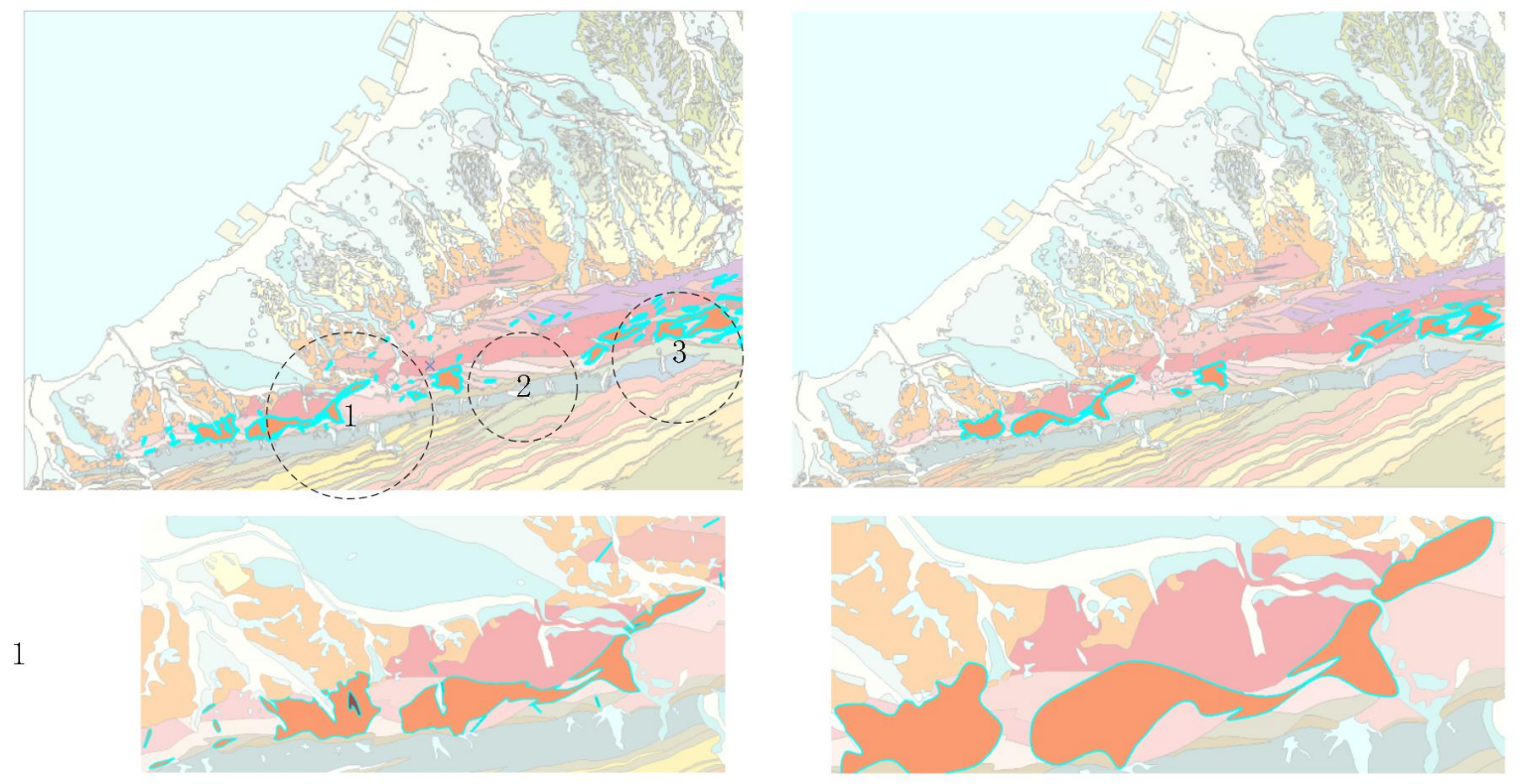

2
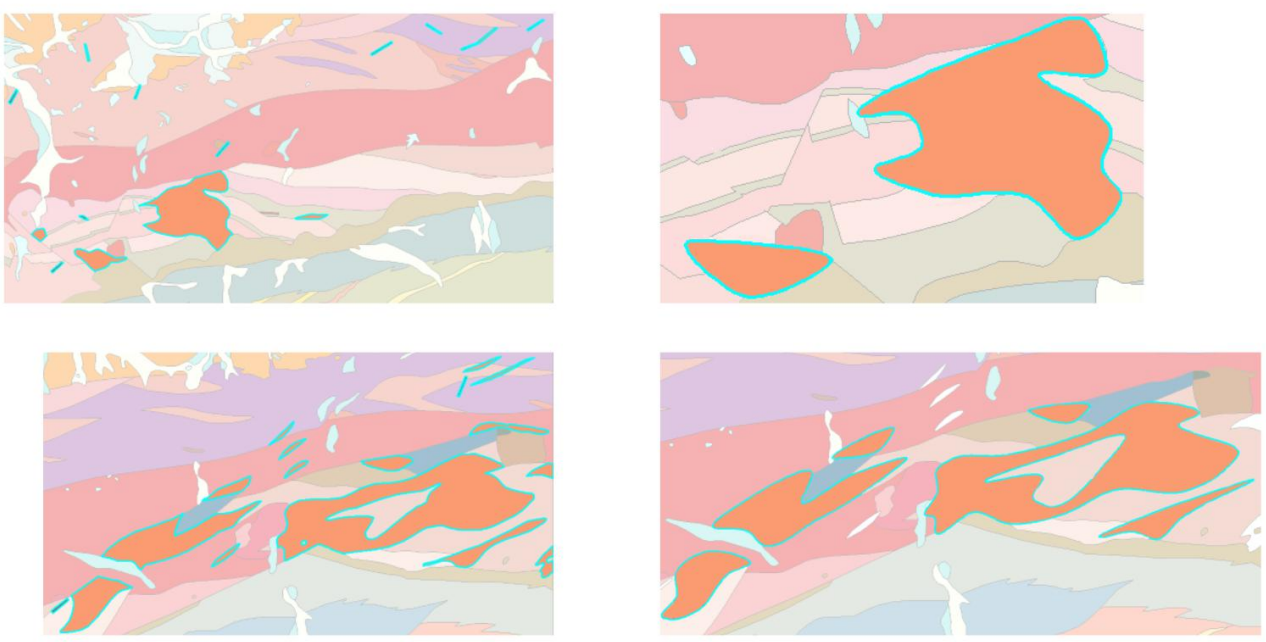

(a) General situation of dykes in Experiment2

(b) generalization results of dykes in Experiment2

Figure 9. Geological map and general situation of dykes in Experiment2

\section{Conclusions}

This paper put forward a new automatic generalization method that considers the influence of the geological process and the original state of the reduction of the dykes. By comparing with the 1:20 million geological map data, it shows that the method can preserve the integrity of the dykes better in the case of automatic generalization, and generalization results of the dykes are more reasonable, and the generalization process is less influenced by the subjective factors. However, the generalization method proposed in this paper is only suitable for general geological map generalization. The thematic geological maps, such as geomorphology, quaternary geological maps or hydrogeological maps, which emphasize the characteristics of sedimentary or hydrological phenomena, the importance of dyke may be reduced, so the generalization method proposed in this paper will no longer apply. According to the use of geological maps, geological map generalization under the premise of considering all kinds of geological weight requirements will become one of the following research directions.

\section{Acknowledgement}

This work was supported by the National Science Foundation of China under Grant No. 41271449.

\section{References}

Experimental data source: https://gbank.gsj.jp/datastore/ download.php 
Ancochea, E., Brändle, J. L., et al. (2003). The felsic dikes of la gomera (Canary Islands): identification of cone sheet and radial dike swarms. Journal of Volcanology \& Geothermal Research, 120(3), 197-206.

Downs T., Mackaness W.(2013). An Integrated Approach to the Generalization of Geological Maps.Cartographic Journal, 39(2):137-15.

Loudon, T. V. (2000). Geoscience after IT. Part B. Benefits for geoscience from information technology, and an example from geological mapping the need for a broad view. Computers and Geosciences, 17(3), A5-A13.

Michael P., Jonathan H., Lisa T. (2004). Patterns of magma flow in segmented silicic dikes at Summer Coon volcano, Colorado: AMS and thin section analysis. Earth and Planetary Science Letters, 219(1):115-169.

Pillewizer, W. (1966). The Principles of Selection, A Means of Cartographic Generalization.Cartographic Journal, 3(1):10-16.

Ressel M W. (2000). Dike-Hosted Ores of the Beast Deposit and the Importance ofEocene Magmatism in Gold Mineralization of the Carlin Trend. Economic Geology, 96(3):666-668.

Scarrow J., Leat P., Wareham C., et al. (1998). Geochemistry of mafic dykes in the Antarctic Peninsula continentalmargin batholith: a record of arc evolution. Contributions to Mineralogy \& Petrology, 131(23):289-305.

Tao, L., Wentao, L. and Shan, K.(2005). Geologic features and tectonic implications of the Tuyon volcano group. Xinjiang Geology, 39(2):137-15.

Tingdong L., Weicui D., Ning Z.(2011). Raise the level of geological map techniques through consulting a wide variety of maps. Journal of Geo-information Science, 13(6), 711-719.

Westerman D., Dini A., et al.(2003). When and where did hybridization occur? The case of the Monte Capanne pluton, Italy. Atlantic Geology, 39(2):147-162.

Zhaohua L., Xinxiang L., Bingzhang W.(2008). Postorogenic dike complexes and implications for metallogenesis. Earth Science Frontiers, 39(2):137-15. 